\title{
DE LA REBELDÍA Y SUS EFECTOS EN EL PROCEDIMIENTO LABORAL DE APLICACIÓN GENERAL
}

\author{
Miguel Zepeda Pinto* \\ Abogado
}

\section{INTRODUCCIÓN}

Desde épocas pretéritas en materia de derecho procesal, y en distintos sistemas jurídicos, se ha tratado de dar una respuesta al fenómeno de la rebeldía, entendiendo por tal la inactividad fundamentalmente respecto del sujeto pasivo en la relación jurídica procesal, en orden a explicar el por qué -frente a esta inactividad- es posible continuar con la tramitación del proceso evitando que dicha conducta tenga el efecto de resultar un obstáculo dentro del mismo a fin de obtener la correspondiente tutela jurisdiccional por parte de quien acciona.

La relación procesal entendida como aquella que liga a los sujetos activo y pasivo con el órgano que ejerce jurisdicción también llamada relación triangular ${ }^{1}$, importa para las partes de la misma, obligaciones y cargas, que deben soportar no sólo quien acciona en miras a lograr un resultado favorable, sino también la contraparte de quien se pretende lo pedido.

La mayoría de la doctrina ${ }^{2}$ concuerdan en que dichas actuaciones si bien no responden a una obligación propiamente tal en el sentido de ser satisfecha, si constituyen cargas para los intervinientes por lo que su incumplimiento tendrá efectos procesales traducidos en la sentencia.

En efecto, no cabe duda que el Derecho Procesal no constituye un fin en si mismo sino que sus normas y principios sirven a la eficacia y cumplimiento del derecho sustantivo, tendiendo al cumplimiento de los derechos y garantías que a nivel Constitucional se consagran, traducido en el llamado debido proceso.

El estadio procesal de rebeldía lo podemos verificar en distintas etapas del proceso laboral, no obstante será materia de nuestro estudio, aquella conducta traducida en la inactividad total del sujeto pasivo que habiendo sido legalmente emplazado mediante la correspondiente notificación de la demanda, asume la actitud de no contestar frente a dicho emplazamiento. Cuando ello sucede estamos frente a la figura jurídica de la rebeldía propiamente tal o inacción absoluta del requerido. Dicha actitud se encuentra contemplada para el caso del sujeto pasivo en nuestro Código del Trabajo Capítulo II Párrafo $3^{\circ}$ Del procedimiento de aplicación general artículo $453 \mathrm{~N}^{\circ} 1$ párrafo séptimo, respecto del demandado que no contestare la demanda.

\footnotetext{
* El presente trabajo es parte de aquél que presenté para la defensa de mi tesis ante el Tribunal de Magister, de la Escuela de Derecho de la Universidad Católica del Norte, en Antofagasta, integrada por los académicos Sra. Ángela Toso M., Sr. Dinko Franulic C., y Sr. Fernando Orellana T. Este último académico además fue profesor guía de mi tesina.

Calamandrei, Piero. Instituciones de Derecho Procesal Civil. Vol. I. Buenos Aires, Argentina: Editorial El Foro, 1996, pp. 333, 334, explica que "Estas personas que colaboran en el proceso (los sujetos del proceso) son, al menos, tres: el órgano judicial, que tiene el poder de dictar la providencia judicial, y las partes: esto es, la persona que pide la providencia ("actor", en el proceso de cognición, "acreedor" en el proceso de ejecución) y aquella frente a la cual la providencia se pide ("demandado", en el proceso de cognición; “deudor” en el proceso de ejecución).

Véase en este sentido Chiovenda, José. Principios de Derecho Procesal Civil. Tomo II. Buenos Aires, Argentina: Editorial Reus, 1925 , pp. $267-268$.
} 
Miguel Zepeda Pinto/De la rebeldia y sus efectos en el procedimiento laboral de aplicación general

Dicho esto, podemos señalar que no será materia de este artículo el tratamiento de la segunda situación contemplada en dicha norma, esto es, la conducta referida al supuesto en que el sujeto pasivo contestando la demanda no negare en ella algunos de los hechos contenidos en ella, ya que dicho supuesto a que la norma hace alusión, no presenta ninguna novedad meritoria de examen o discusión respecto de los efectos asignados para tal evento, sin perjuicio que analicemos brevemente la procedencia de la misma en el sentido que nuestro legislador la contempla.

De este estudio se podrán obtener conclusiones para la procedencia de argumentar sobre la correcta o incorrecta procedencia de la norma citada y su aplicación en el procedimiento laboral. No obstante, haremos un esfuerzo por desentrañar el verdadero sentido de la rebeldía en los efectos que nuestro legislador establece. Para dicha tarea resulta de interés una mirada al antiguo paradigma sobre el cual discurren algunos respecto al motivo del por qué frente al silencio del sujeto pasivo se recibe la causa a prueba, asunto que para efectos prácticos en nuestro actual sistema procesal civil constituye una discusión bizantina, pero que por el contrario en nuestro procedimiento laboral cobra real importancia, cuestión que no es menor en atención a los desajustes que puede producir a la hora de resolver el asunto sometido a conocimiento y decisión de nuestros tribunales laborales.

Los objetivos generales se centrarán en el estudio de la rebeldía, y el objetivo específico se referirá al correcto sentido y alcance de la admisión tácita de hechos y sus efectos.

\section{DE LA REBELDÍA. PALABRAS PREVIAS}

El fenómeno de la rebeldía ha recibido una pluralidad de tratamientos legislativos en la historia y el derecho comparado. El acudir al derecho comparado no persigue simplemente comparar normas, sino más bien sistemas que responden a una realidad histórica y cultural diversa. ${ }^{3}$ Esta es la ocasión para referirnos brevemente a dos de los sistemas más aceptados en cuanto al instituto -no los únicos- que si bien difieren sustancialmente en sus efectos, no obstante coinciden y tienen su fundamento en una ficción jurídica. De esta manera ambos sistemas responden frente al supuesto de inactividad procesal del sujeto pasivo otorgando respuestas frente a dicha conducta en sentido de evitar la paralización o entorpecimiento del proceso resguardando la tutela jurisdiccional de aquella parte diligente en el mismo. Ambos sistemas propugnan en sentido afirmativo la posibilidad y procedencia de seguir adelante un proceso en ausencia de una de las partes evitando al mismo tiempo una desigualdad en favor de aquella parte participativa en desmedro del sujeto ausente, sin vulnerar con ello las garantías de un proceso justo o como lo califica nuestro legislador constitucional, proceso previo legalmente tramitado.

Nos referimos a los sistemas de la ficta confessio y de la ficta litis contestatio ${ }^{4}$. El primero tiene su procedencia y aplicación en los sistemas procesales de origen germano mayoritariamente. Dicho sistema entiende que frente a los hechos alegados por una de las partes y no contradichos o negados por la contraparte se entienden como reconocidos y aceptados por la misma. En este sentido se debe tener en cuenta que la actitud diligente en el proceso corresponderá tanto al sujeto activo que sostiene una pretensión como al sujeto pasivo que se defiende frente a la misma. Para el caso del sujeto pasivo o demandado su conducta se asimila fictamente a una confesión, entendiendo que reconoce como efectivas las alegaciones del demandante. Es una solución que permite

\footnotetext{
Orellana, Fernando; Pérez Ragone, Álvaro. "Radiografía de la rebeldía en el proceso civil: Tópicos hacia una adecuada regulación en la nueva justicia civil”, en: Ius et Praxis, año 13, nº 2, 2007, p. 16.

$4 \quad$ Ibid., pp. 17 y ss.
} 
sortear el problema de la inactividad de una de las partes, a fin de resolver el asunto sometido a conocimiento del juez, arribando a una sentencia. Conveniente resulta destacar que para este sistema el efecto que se le asigna frente a la rebeldía, tiene el valor de una confesión y no de una mera presunción, ya que esta última entiende que los hechos alegados contienen una presunción de veracidad, pero dicho efecto emana de la simple conducta del actor que sostiene tales hechos. En cambio por la confesión se entiende la manifestación de voluntad del requerido, que aunque ficta, reconoce la efectividad de los hechos sostenidos por el requirente.

Por otra parte, el sistema de la ficta litis contestatio entiende que frente al silencio o inactividad del demandado, enfrentado a una demanda, éste controvierte todo lo alegado por el sujeto activo, efecto construido igualmente en una ficción jurídica respecto de la conducta rebelde de una de las partes. Este segundo sistema presenta mayor consistencia que el anterior, puesto que el razonamiento en su aplicación deviene en un efecto de gran importancia traducido en el cumplimiento de uno de los requisitos de procedencia para ser admitidos los hechos a prueba, esto es, que sean controvertidos. De esta manera se hace lugar a la etapa probatoria con el mérito de dicha controversia haciendo posible el recibimiento de la causa a prueba.

Si analizamos la actitud del llamado rebelde, se puede afirmar con certeza que el efecto de la ficta litis contestatio no es un mero capricho, sino por el contrario, se corresponde perfectamente con el sentido procesal que le debemos asignar.

No debemos olvidar que el sujeto pasivo debidamente emplazado puede contestar la demanda ya sea oponiendo excepciones que pueden ser dilatorias y/o perentorias, las segundas contienen la intensión de desvirtuar la pretensión del actor, restándole toda fuerza. Puede además deducir alegaciones o defensas y reconvenir.

En efecto, el artículo 452 inciso $2^{\circ}$ del Código del Trabajo ${ }^{5}$ expresa que "la contestación deberá contener una exposición clara y circunstanciada de los hechos y fundamentos de derecho en los que se sustenta, las excepciones y/o demanda reconvencional que se deduzca, así como también deberá pronunciarse sobre los hechos contenidos en la demanda, aceptándolos o negándolos en forma expresa y concreta".

El requisito que exige la norma en cuanto a pronunciarse sobre los hechos contenidos en la demanda negándolos, se corresponde con las llamadas alegaciones o defensas, distintas en sus efectos respecto de las excepciones. Entre ambas hay diferencias, y numerosos tratadistas como Casarino $^{6}$, Carnelutti ${ }^{7}$, Anabalón ${ }^{8}$ y Chiovenda ${ }^{9}$, señalan el distingo así como su importancia.

El sujeto pasivo se defiende con alegaciones o defensas cuando sencillamente niega los hechos que sirven de fundamento al derecho invocado por el actor, estrategia procesal que pone al actor en la situación de tener que acreditar la existencia y veracidad de los hechos contenidos en su demanda, y que para el sistema de la ficta litis contestatio tiene su correspondencia en cuanto se entiende que por el silencio traducido en la no contestación se están negando todos los hechos pasando a adquirir estos la calificación jurídica de controvertidos.

\footnotetext{
En adelante CT.

Casarino Viterbo, Mario. Derecho Procesal Civil. Tomo IV. Santiago, Chile: Editorial Jurídica de Chile, 1997, pp. 57-58, sostiene que "la alegación o defensa, en cambio es la total negación del derecho reclamado, desconociéndolo en su nacimiento mismo y fundado en los requisitos de derecho invocados por el actor y que el juez debe conocer, de modo que, contestando el demandado, mediante una alegación o defensa, nada tendrá que probar".

Carnelutti, Francesco. Instituciones del Proceso Civil. Vol. I. -4º edición-. Buenos Aires, Argentina: Librería El Foro, 1997, pp. $34-35$.

Anabalón Sanderson, Carlos. El Juicio Ordinario de Mayor Cuantía. Santiago, Chile: Editorial Jurídica de Chile, 1954 , p. 173.

Chiovenda, José, op. cit. (n. 2), p. 315.
} 
Miguel Zepeda Pinto/De la rebeldía y sus efectos en el procedimiento laboral de aplicación general

De esta manera, el sujeto activo quien se encuentra solitario en la relación procesal por la inactividad de su contraparte, se verá en la necesidad de probar los hechos que sostienen el derecho invocado traducido en la pretensión. Por medio de esta ficción de negación entonces el juez procederá a recibir la causa a prueba. Con esto no estamos afirmando que nuestro procedimiento procesal laboral adhiera al sistema de la ficta litis contestatio, sin embargo podemos observar que el mismo presenta -y a pesar de la citada facultad del juez- en muchos casos, el razonamiento propio de dicho sistema.

Un supuesto distinto se verifica, si el demandado legalmente emplazado al juicio adopta la actitud de defenderse contestando la demanda, y al hacerlo no se hace cargo de algunos de los hechos fundantes de la acción del actor, en definitiva se verificará una aceptación tácita respecto de los mismos. Este escenario, que en nuestro concepto se traduce en un evidente error del sujeto pasivo toda vez que podría simplemente negar tales hechos de forma expresa y concreta obligando con ello al actor a probar la efectividad de lo alegado; no presenta mayor análisis para nuestro estudio y se corresponde con una admisión tácita ante la omisión voluntaria de hacerse cargo de las imputaciones contenidas en el libelo de demanda.

Por ende, la estimación facultativa del juez no estará más que encuadrándose en el correcto sentido que se le debe dar a la norma, dado que el rebelde no puede con su conducta ponerse en una situación de ventaja respecto de su contraparte. Esto se explica ya que la norma es del tipo imperativa y por lo mismo contiene un deber procesal que se debe observar. En efecto, el artículo 452 inciso $2^{\circ}$ reza la fórmula "deberá pronunciarse sobre los hechos contenidos en la demanda..." Por lo mismo su incumplimiento amerita el efecto procesal referido.

En resumen, no podrían encontrarse en una misma situación jurídica quienes dan cumplimiento a la norma con quienes no lo hacen, puesto que su implementación procesal está dirigida a un correcto desenlace del procedimiento a objeto de lograr la máxima certeza en la correspondencia del derecho sustantivo al que sirve.

Hecha esta prevención, entraremos a la tratativa de la rebeldía y fijación de los hechos a probar, cuestión de mucha importancia e interés para el tema propuesto.

\section{LA REBELDÍA Y FIJACIÓN DE HECHOS A PROBAR}

Todo proceso supone existencia de hechos respecto de los cuales se invocará el derecho aplicable que se reclama y que sirven de fundamento a lo pedido. Incluso en aquellos casos en que el sujeto activo litiga en rebeldía de su contraparte, los hechos alegados serán objeto de prueba. Del porqué se reciben los hechos a prueba, algo ya se trató anteriormente. No obstante ello, más adelante volveremos sobre el tema intentando dar una reflexión de modo algo más preciso no por ello pretenciosa. La situación de rebeldía del sujeto válidamente emplazado que no contesta la demanda -y digo válidamente ya que de no serlo estamos ante una situación diversa- no impedirá la sustanciación del juicio en que ella se verifica. El artículo $453 \mathrm{~N}^{\circ} 3$ del CT expresa que: "Contestada la demanda sin que se haya opuesto reconvención o excepciones dilatorias, o evacuado el traslado conferido de haberse interpuesto éstas, el tribunal recibirá de inmediato la causa a prueba, cuando ello fuere procedente, fijándose los hechos a ser probados". El inciso $2^{\circ}$ previene, "De no haber hechos sustanciales, pertinentes y controvertidos, el tribunal dará por concluida la audiencia y procederá a dictar sentencia”.

Ahora bien, como podemos observar requisito de procedencia para que el tribunal proceda a recibir la causa a prueba fijando los hechos a probar, es que estos sean sustanciales, pertinentes 
y controvertidos. Esta última característica es materia de conflicto en el supuesto que estudiamos, ya que en el silencio del rebelde quien puede aseverar que los hechos revisten el carácter de controvertidos, salvo sirviéndonos de la ficción de negación. Si nos detenemos en la norma podemos constatar que la misma no contempla la situación de rebeldía, sino por el contrario, hace alusión a todos los casos en que precisamente no se verifica rebeldía del sujeto pasivo. En el mismo sentido de falta de rebeldía, se explican los efectos de no cumplirse con los requisitos copulativos que deben presentar los hechos para ser admitidos a prueba, resolviendo dar por concluida la audiencia preparatoria y dictar sentencia derechamente.

El hecho que la norma del $453 \mathrm{~N}^{\circ} 3$ del CT insista respecto del recibimiento de la causa a prueba "cuando ello fuere procedente", nos indica el supuesto de cumplirse con las situaciones que enumera al comienzo de la misma, dentro de las cuales no se contempla la rebeldía. Entonces la pregunta que nos hacemos es ¿cuándo es procedente?: Es procedente cuando se verifiquen los supuestos a que la misma disposición hace alusión y que describe detalladamente.

Lo anterior nos hace reflexionar en el sentido de aceptar que la decisión del juez de recibir la causa a prueba "cuando ello fuere procedente" sería el resultado de estimar los hechos invocados por el actor con el mérito de controvertidos, y que sin embargo no han sido negados ni aceptados por el sujeto pasivo. La citada norma, así como ninguna otra, resuelve la cuestión de que frente a la rebeldía se proceda a recibir la causa a prueba como sucede en los hechos. Como tampoco resuelve el porque en otros, se proceda a inferir por el juez que en razón de la rebeldía no hay hechos controvertidos, dando lugar a poner término a la audiencia y procediendo a dictar sentencia. Y en este sentido, este autor no comparte en lo pertinente el argumento de quien sostiene que “...para que tenga lugar la admisión tácita de los hechos afirmados por el demandante, deben constar en el proceso antecedentes que hagan verosímil dicha admisión, de lo contrario, debe recibir la causa a prueba..."

En efecto, sostener lo anterior se traduce en afirmar que de los meros antecedentes señalados por el demandante en su libelo que pueden parecer muy convincentes, es decir los hechos esgrimidos para la procedencia del derecho en que funda la pretensión, se podría dictar sentencia derechamente sin recibir la causa a prueba. Esto es del todo errado, no sólo por lo antes dicho, sino que además porque el actor debe necesariamente probar sus alegaciones para obtener su pretensión, y con mayor razón aún si se encuentra enfrentado a la verificación de rebeldía por parte de aquel respecto del cual se pretende y que en nada aporta a la actividad procesal desplegada. Pero por sobre todo, por que es el propio procedimiento que en su integración conlleva implícita la manera de resolver. ¿Los referidos antecedentes que hagan verosímil la admisión tácita y que deben constar en el proceso, acaso no se obtienen de la aportación de prueba? Podríamos pensar que no necesariamente. De importancia resulta destacar en lo pertinente, que el artículo 446 del CT referido a los requisitos que deberá contener la demanda, no exige en modo alguno el acompañamiento de documentos que sirvan de fundamento a la acción impetrada, sino que en su numeral cuarto exige "La exposición clara y circunstanciada de los hechos y consideraciones de derecho en que se fundamenta", agregando además en su inciso segundo que "Sin embargo, deberá presentarse conjuntamente con la demanda, aquella que dé cuenta de las actuaciones administrativas que se refieren a los contenidos en esa".

La situación por dicho autor descrita, en que si sería posible la admisión tácita de los hechos dando lugar derechamente a la dictación de sentencia sin recibir la causa a prueba, corresponde al

\footnotetext{
10 Fernández Toledo, Raúl. Las facultades y deberes del juez en materia probatoria en el proceso laboral. Análisis crítico. Santiago, Chile: Thomson Reuters PUNTOLEX, 2011, pp. 219-234.
} 
Miguel Zepeda Pinto/De la rebeldía y sus efectos en el procedimiento laboral de aplicación general

supuesto contemplado en el artículo $453 \mathrm{~N}^{\circ} 3$, esto es, que "contestada la demanda, sin que se haya “opuesto reconvención" -expresión mal utilizada por el legislador toda vez que la reconvención o demanda reconvencional su naturaleza jurídica no corresponde a alegaciones o defensas, sino que a una pretensión del demandado original que se defiende- o excepciones dilatorias, o evacuado el traslado conferido de haberse interpuesto éstas, el tribunal estimare que no hay hechos que revistan la calidad de sustanciales, pertinentes y controvertidos, caso en el cual dará por concluida la audiencia y procederá a dictar sentencia".

Como podemos observar, este supuesto jurídico requiere de la participación del sujeto pasivo que contesta la demanda, y excluye además el supuesto contemplado en el artículo 452 inciso $2^{\circ}$ en cuanto a la aceptación de los hechos contenidos en la demanda, ya que evidentemente dicho supuesto dice relación con la admisión expresa y no tácita.

Por tanto podemos afirmar sin temor a equivocarnos que para que tenga lugar la admisión tácita de los hechos afirmados por el demandante, éste debe necesariamente aportar antecedentes probatorios que hagan efectivamente verosímil los hechos invocados. Es decir, deberá probar los hechos que alega, ya que en el supuesto de no lograrlo, no podría el juzgador estimar que éstos revisten el mérito suficiente para dar lugar a estimar los mismos como tácitamente admitidos dando lugar a lo pedido. Necesariamente se requerirá, de un grado suficiente en la prueba que de lugar a la admisión ${ }^{11}$.

No obstante esta postura que expongo, analizaremos aquella que entiende que la actitud de rebeldía del sujeto pasivo frente a la demanda importa derechamente la inexistencia de hechos que revistan la calidad de controvertidos, y por ende, perfectamente procedente la conclusión de la audiencia preparatoria dando lugar a la dictación de sentencia, estimándose por el juez los hechos como tácitamente admitidos, no procediendo a recibir la causa a prueba. Postura que advertimos muy frecuentemente acogida por nuestros tribunales laborales.

\section{LA ADMISIÓN TÁCITA DE HECHOS NO PROBADOS}

Particular interés presenta la tratativa de la admisión tácita de hechos no probados. Curiosamente cabe señalar, que consultados algunos jueces laborales ${ }^{12}$ por la manera de proceder frente a la rebeldía del demandado, éstos estiman casi al unísono, que en este contexto estamos ante la falta de hechos controvertidos, razón por lo cual, se debe resolver en aplicación doctrinaria de la ficta confessio. Respuesta que este autor no comparte, como más adelante se explicará. Reiterados

\footnotetext{
11 Así, Claudio Fuentes Maureira cita a Clermont quien señala:"en otras palabras, el juez sólo está autorizado a dar por probado un hecho cuando concluye que es más probable que haya ocurrido a que no haya ocurrido en base a la evidencia, siempre que la prueba disponible satisfaga requisitos de calidad y suficiencia mínimos que hagan que la probabilidad de ocurrir el hecho llegue al menos al 50\%, por el contrario, si esa probabilidad es menor al 50\%, entones estamos a solo una posibilidad y el juez no está autorizado a declarar que ha sido acreditado". Fuentes Maureira, Claudio. "Consideraciones en torno a la idea del estándar de convicción en el Proceso Civil”. En: Leturia I., Francisco J. (Editor). Justicia Civil y Comercial: Una Reforma Cercana. Santiago: Ediciones Libertad y Desarrollo, 2011, pp. 173-205.

12 Entre otros Chávez Castillo, Yohana, Juez Presidente Juzgado Letras del Trabajo de Antofagasta.
} 
fallos dan cuenta de ello ${ }^{13}$, sin embargo y al mismo tiempo, muchos otros dan cuenta de lo con$\operatorname{trario}^{14}$.

Una cuestión a examinar, respecto de esta expresión que utiliza nuestro legislador laboral al referirse a la citada estimación facultativa del juez, radica en lograr visualizar de modo correcto los efectos jurídicos en su aplicación. A este respecto, Carrasco distingue los efectos que produce la admisión de hechos en relación con la presunción iuris tantum, el allanamiento tácito y la ficta confessio, sosteniendo que dependiendo de ella el juez podrá limitar o no, en mayor o menor medida, la aplicación de la referida sanción y también podrá determinar si es necesario recibir o no la causa a prueba ${ }^{15}$.

a) La presunción iuris tantum se corresponde con una presunción simplemente legal, y que por tanto admite prueba en contrario. Así se contempla normativamente en la legislación laboral argentina (Capital Federal) ${ }^{16}$ que establece ante la rebeldía, la presunción cierta de los hechos expuestos en la demanda salvo prueba en contrario. Similar tratativa recibe en la legislación laboral peruana ${ }^{17}$. Citado esto, podemos verificar que en nuestra legislación laboral la admisión tácita de hechos no corresponde a una presunción legal, ya que ella se encuentra establecida respecto de su procedencia de aplicación en la etapa de sentencia, así como expresa claramente el artículo $453 \mathrm{~N}^{\circ} 1$ párrafo 7 . Al respecto nuestra citada norma no apercibe al sujeto pasivo en el

13 "SEGUNDO: Que, el demandado no contesto la demanda y tampoco compareció a la audiencia, ante lo cual el Tribunal, considerando que no existía controversia, se abstuvo de recibir la causa a prueba y se procedió a dictar sentencia derechamente. TERCERO: Que, ante la falta de contestación de la demanda, el Tribunal hará efectiva la facultad que contempla el artículo $453 \mathrm{~N}^{\circ}$ 1 inciso $6^{\circ}$ del Código del Trabajo, dando como tácitamente admitidos los hechos contenidos en la demanda”. "QUINTO: Que, considerando que por aplicación de la facultad legal, este sentenciador consideró como tácitamente reconocidos los hechos fundantes de la demanda,... motivo por el cual, acogerá la demanda impetrada, ordenando el pago de la indemnizaciones y prestaciones que en derecho corresponda otorgar". SENTENCIA del Juzgado de Letras del Trabajo de Antofagasta, 10 de marzo de 2011, R.I.T. O-452011. [en línea]. <www.poderjudicial.cl.> [consulta: 5 mayo 2011]. En el mismo sentido, véase SENTENCIA del Juzgado Letras del Trabajo de Antofagasta, 16 de marzo de 2011, R.I.T. O-66-2011.

14 "SEGUNDO: Que, dońa Raquel Rocío Prado Flores, no compareció al proceso, de tal manera que el juicio se siguió en su rebeldía. SEXTO: Que, del análisis de las pruebas acompañadas a la causa, de conformidad a las reglas de la sana crítica y teniendo, especialmente presente que la trabajadora no contestó la demanda, y por ende resulta factible tener por reconocidos tácitamente los hechos expuestos en la demanda, se comprueba que el contrato de trabajo que liga a las partes es de plazo fijo cuyo vencimiento ocurrió el día 15 de febrero de 2011, de tal modo que se acogerá la demanda otorgando la autorización solicitada. SENTENCIA del Juzgado del Trabajo de Antofagasta, 6 de abril de 2011, R.I.T. O-58-2011. [en línea]. www.poderjudicial.cl [consulta: 17 mayo 2011]. En este mismo sentido, "TERCERO: Que habiendo sido emplazada la parte demandada, aquella no contesto la demanda en tiempo y forma, se celebró la audiencia preparatoria en su rebeldía, por lo que se tuvo por fracasado el llamado a conciliación y el Tribunal estableció los hechos sustanciales, pertinentes y controvertidos, fijando como aquellos los siguientes... QUINTO: Que el Artículo $453 \mathrm{~N}^{\circ} 1$ inciso $7^{\circ}$ del Código del Trabajo, expresa que, en aquellos casos en que la parte demandada omitiere el trámite de contestación de demanda y asimismo se mantuviese en rebeldía en el transcurso del juicio, el Tribunal podrá en la sentencia definitiva entender como reconocidos tácitamente los hechos contenidos en la demanda, ingresados por la parte demandante; que desde esa perspectiva, siendo facultativo para este Tribunal, esta Magistratura entenderá en este estadio procesal que efectivamente en la especie la parte demandada ha reconocido tácitamente los hechos contenidos en la demanda y los fundamentos de derecho que ella contiene". SENTENCIA del Juzgado Letras del Trabajo de Copiapó, 6 de mayo de 2011, R.I.T. O-30-2011. [en línea]. <www.poderjudicial.cl> [consulta: 25 mayo 2011].

15 Carrasco Poblete, Jaime. La Rebeldía en el Procesos Civil y Laboral. Santiago, Chile: Abeledo Perrot Legal Publishing, 2010 , p. 126.

16 Ante la rebeldía del demandado en contestar la demanda, la Ley 18.345 de Procedimiento Laboral - Capital Federal en su artículo 71 inciso $3^{\circ}$ dispone "Si el demandado legalmente citado no contestare la demanda en el plazo previsto en el artículo 68 será declarado rebelde, presumiéndose como ciertos los hechos (CONTINUACIÓN) expuestos en ella, salvo prueba en contrario". [en línea]. <www.leyeslaborales.com.ar> [consulta: 3 julio 2012].

17 La Ley Procesal del Trabajo $N^{\circ} 26.636$ en su artículo 24 sobre la rebeldía, establece que "Si transcurrido el plazo para contestar la demanda, el demandado no lo hace, incurre en rebeldía. Esta declaración causa presunción legal relativa sobre la verdad de los hechos expuestos en la demanda, salvo que habiendo varios emplazados en forma solidaria alguno conteste la demanda o cuando el juez declare en resolución motivada que no le producen convicción.” [en línea]. <www.ucc.ed.ar>. [consulta: 3 julio 2011 ]. 
Miguel Zepeda Pinto/De la rebeldia y sus efectos en el procedimiento laboral de aplicación general

sentido de presumirse efectivos los hechos, sino de estimarse por el juez "como tácitamente admitidos".

Por tanto, presunción legal y admisión tácita no comparten una misma naturaleza jurídica, ya que esta última supone una manifestación implícita del sujeto pasivo en sentido de conformidad con los hechos que hace innecesaria la prueba. En cambio la presunción iuris tantum admite prueba.

b) En cuanto al allanamiento y la admisión tácita, salta a simple vista una diferencia radical; el allanamiento dice relación con un acto de disposición del demandado respecto de la pretensión procesal que deviene además en que el juez dicte normalmente sentencia estimatoria a favor del actor $^{18}$, en cambio la admisión tácita se refiere a hechos, y no al derecho, no importando en razón de ello necesariamente una sentencia estimatoria.

Sin embargo, Carrasco sostiene que "la admisión de hechos puede ser tácita o presunta, mientras que el allanamiento debe ser expreso". Discrepamos de esta última afirmación, sosteniendo que el allanamiento no sólo puede ser expreso, lo que supone la regla general, sino que perfectamente puede haber allanamiento tácito. En efecto, supongamos que en juicio de procedimiento de aplicación general por despido indirecto y cobro de prestaciones, el demandado no contesta la demanda, y no obstante ello, consigna en la cuenta corriente del tribunal el total de las sumas demandadas, además de solicitar al mismo tiempo liquidación de costas. Hay aquí un verdadero allanamiento tácito, ya que la actividad desplegada por el demandado se traduce en satisfacer la pretensión sin mediar sentencia declarativa que condene aún a dicha parte al pago de las prestaciones demandadas. Al mismo tiempo dicha conducta de allanamiento tácito, hace innecesario un juicio declarativo.

En este sentido, podemos aseverar que para el caso propuesto, no hay decisión del asunto sometido a conocimiento del tribunal, y por ende, en sentido estricto no podemos afirmar que estamos ante un cumplimiento. Se ha satisfecho la pretensión, pero no se puede sostener que con ello se ha dado cumplimiento pues no hay sentencia que así lo ordene. Distinto será el efecto en el supuesto de encontrarnos ante un procedimiento ejecutivo, ya que en este, la situación antes descrita se corresponde efectivamente con un cumplimiento. Todo lo anteriormente dicho sin perjuicio de que la rebeldía del demandado que no contesta la demanda, no constituye para el caso estudiado allanamiento alguno.

En resumen, admisión tácita y allanamiento no son lo mismo, este último lo efectúa necesariamente el demandado, en cambio la admisión tácita opera en virtud de la ley.

c) Por último, el citado autor analiza la admisión tácita respecto de la ficta confessio señalando que "ambas pueden asimilarse, ambas se refieren a hechos y no al derecho, pero la primera releva de la prueba a la parte que beneficia, en cambio, la segunda constituye un medio de prueba que debe ser valorado y puede ser desvirtuado por prueba contraria”. Aseveración esta última que este autor no comparte en modo alguno, toda vez que doctrinariamente, la ficta confessio o confesión ficta consiste precisamente en reconocerse los hechos alegados -aunque de manera ficticia- como efectivos, dando lugar a su efecto esencial, cual es, hacer innecesaria la etapa de prueba dando lugar a una sentencia, a pesar de la actitud del requerido. Por ende, sostener que "esta constituye un medio de prueba que debe ser valorado".... creemos un error.

18 Carrasco Poblete, Jaime, op. cit. (n. 15), p. 16. 
A este respecto, Carrasco cita a Bachmaier, la cual sostiene que "la admisión, es por tanto, un medio de fijación de hechos no probatorio, pues con ella no se aporta ningún conocimiento o ciencia acerca de la veracidad de los mismos, a diferencia de lo que sucede en la confesión" ${ }^{19}$. Esta afirmación de la autora española es correcta, sin embargo necesariamente debemos concluir que la confesión a la que alude, corresponde a la confesión expresa y no tácita, ya que esta última releva de prueba. Concordante con este alcance, la misma refiere que "los hechos que se tienen por confesados pueden ser contrastados por otros medios de prueba, pero los hechos que se tienen por admitidos no pueden ser contradichos por otros elementos probatorios pues no son objeto de la prueba" ${ }^{20}$. Por tanto podemos afirmar, que tanto la admisión tácita de hechos como la ficta confessio operan en virtud de ley, y ambas producen el efecto de hacer improcedente la prueba.

Sin embargo, podemos observar que de esta comparación no se arrojan otras diferencias que para el caso en estudio resultan de una importancia fundamental. En efecto, si nos detenemos en dicho análisis podemos concluir que la ficta confessio operará necesariamente respecto de todos los hechos alegados por el actor, en cambio ante la rebeldía, la admisión de hechos se puede verificar respecto de todos los hechos, como también ser procedente en su aplicación y efectos respecto de sólo algunos hechos, o incluso de uno sólo.

Lo anterior nos conduce a concluir necesariamente que ante la rebeldía, la admisión tácita de hechos puede operar perfectamente con la prueba, y ello confirma y explica el que la misma no importe necesariamente una sentencia estimativa. En cambio, la ficta confessio no produce el mismo efecto procesal.

Hecho el precedente análisis, podemos concluir que la admisión tácita de hechos que contempla nuestro legislador procesal laboral, no se corresponde ni en su naturaleza jurídica ni efectos con una presunción iuris tantum, ni allanamiento tácito, ni ficta confessio.

\section{LA CALIFICACIÓN DE LOS HECHOS NO ES RESULTADO DE LA REBELDÍA}

Si analizamos la jurisprudencia de nuestros tribunales laborales, podemos observar que frente a la rebeldía del demandado, muchos fallos se pronuncian en la audiencia preparatoria, estimando por el juez la falta de controversia. Sin embargo, en otros se procede a recibir la causa a prueba.

Lo anterior, y muy a pesar de las diversas opiniones al respecto, devela una verdad procesal: La contumacia del sujeto pasivo no determina el que los hechos se estimen como controvertidos o no controvertidos. Y ello sin colisionar en modo alguno con la potestad del juez que frente a la rebeldía proceda a estimar facultativamente, si así lo considera, los hechos contenidos en la demanda como tácitamente admitidos.

No debemos perder de vista el hecho que, no estamos discutiendo o poniendo en tela de juicio la citada facultad del juez, sino que analizando la situación de estimarse por el juez los hechos alegados en la demanda y no probados, como controvertidos o no en razón de la rebeldía, dando lugar con ello a la admisión tácita o no de los mismos, puesto que de ello dependerá el resultado en la decisión final traducida en la sentencia.

Así las cosas, nuestros jueces dirán que frente a dicha situación, el uso de la facultad del artículo $453 \mathrm{~N}^{\circ} 1$ inciso séptimo del CT, es aplicable para el caso en que el mérito del proceso

\footnotetext{
Ibid., p. 128.

$20 \quad$ Ibid., p. 128.
} 
Miguel Zepeda Pinto/De la rebeldía y sus efectos en el procedimiento laboral de aplicación general

hace aconsejable su procedencia en razón de lo pedido por el demandante, y que en razón de lo mismo, dicha facultad de estimar como admitidos los hechos contenidos en la demanda frente a la rebeldía del demandado es la consecuencia legal en su aplicación, y por lo mismo ello explica que los hechos no tengan la calificación de controvertidos resultando en la dictación de sentencia sin proceder a recibir la causa a prueba.

Y ello en plena concordancia con nuestro procedimiento laboral vigente tendiente a no dilatar por la inactividad del demandado la tramitación del juicio, fundado en el perjuicio que ello genera para el trabajador. Así lo entiende la mayoría de jueces consultados ${ }^{21}$ al respecto, plasmado además en la jurisprudencia pertinente ${ }^{22}$. Sin embargo, dichos argumentos no satisfacen ni menos explican el porqué frente a la rebeldía, en unos casos se proceda a estimar los hechos como controvertidos y en otros no, resolviendo para este último no recibir la causa a prueba.

Siguiendo esta idea, en algunos casos lo que se discute recurriendo de nulidad de la sentencia, es otra cosa distinta: el no ejercicio de esta facultad por el juez. En efecto, algunos consideran que frente a la no contestación de la demanda, el juez debe necesariamente hacer uso de esta facultad legal, dando lugar a lo pedido. Sin embargo ello no es correcto como se puede apreciar muy claramente en un fallo de la Corte de Apelaciones de Punta Arenas:

"SEXTO: Que, de otra parte se invoca....que la sentenciadora omitió en forma arbitraria el ejercicio de la facultad que le otorga el 453 del Código del Trabajo, para cuando no se contesta la demanda; cuestión que no comparten, tampoco, estos sentenciadores, por cuanto tal y como lo establece el artículo $453 \mathrm{~N}^{\circ} 1$ del Código del Trabajo en su párrafo penúltimo, cuando el demandado no contestare la demanda, -que es lo que ocurrió en la especie -, o de hacerlo no negare en ella alguno de los hechos contenidos en la demanda, el juez en la sentencia definitiva podrá estimarlos como tácitamente admitidos; de lo que se infiere que la Sra. Juez a quo pudo o no ejercer tal facultad, y siendo efectivo que no lo hizo, ello encuentra suficiente fundamento en la motivaciones Décima a Décimo Quinta del fallo recurrido, con lo que no resulta admisible sostener que la Juez a quo omitió, arbitrariamente, el ejercicio de una potestad procesal que, por lo demás, le era facultativa, conforme al texto expreso de la Ley"23.

El citado fallo, corresponde a uno de los casos en que frente a la rebeldía del demandado se procedió a recibir la causa a prueba. En dicho sentido se explica que la demandante recurra de nulidad aduciendo que la juez debió haber ejercido dicha facultad, caso en el cual obtendría sentencia a favor. No obstante, ello no fue así, y el fallo resuelve no acoger la demanda en el fondo. Esta jurisprudencia, es uno de los mejores ejemplos que da cuenta fehacientemente que el razonamiento de estimar los hechos alegados por el actor como necesarios de prueba, es el mejor camino para obtener una decisión correcta, lo más acertada posible y lo menos errada también. En cambio, colocados en el supuesto que el juez hubiese estimado en razón de la rebeldía la falta de hechos controvertidos procediendo a fallar sin recibir la causa a prueba, hubiese importado un

21 En dicho sentido opina JOHANA CHÁVEZ CASTILLO, Juez Presidente del Juzgado del Trabajo de Antofagasta. Por su parte la magistrado titular de dicho tribunal, SOL MARÍA LÓPEZ PÉREZ sostiene que opera el principio pro operario contenido en nuestro Derecho Laboral.

22 En relación con la aplicación del artículo $453 \mathrm{~N}^{\circ} 1$ inciso $7^{\circ}$, "QUINTO: Que el juez de la causa ha hecho uso de la facultad discrecional que le confiere el legislador en aras a imprimir celeridad a las causas laborales”. Corte de Apelaciones de Valparaíso, 5 de mayo de 2009, Rol 80-2009. [en línea]. <www.poderjudicial.cl>. [consulta: 7 julio 2011].

23 Corte de Apelaciones de Punta Arenas, 13 de septiembre de 2008, rol Nº 9-2008. [en línea]. <www.poderjudicial.cl >. [consulta: 11 mayo 2011]. 
resultado totalmente inverso, jurídicamente errado en lo que el derecho busca como herramienta a objeto de obtener justicia o lo más cercano a dicho concepto.

\section{DE POR QUÉ DEBE RECIBIR LA CAUSA A PRUEBA. NI FICTA LITIS CONTESTATIO NI FICTA CONFESSIO}

Conveniente nos parece referirnos también, en sentido general, respecto de una pregunta difícil para algunos de desentrañar: Del por qué ante la falta de actividad del sujeto pasivo que accione controvirtiendo los hechos esgrimidos por el actor se debe proceder a recibir la causa a prueba. Trataremos de explicar esta cuestión sin entrar en grandes formalismos a fin de lograr un lenguaje sencillo y claro que resulte liviano en su comprensión.

Desde épocas pretéritas se ha enseñado en las diversas escuelas de derecho de nuestro país en materia procesal civil que el silencio no otorga ${ }^{24}$. Es decir, que por el silencio (referido al sujeto pasivo) no se entiende que se esté afirmando lo sostenido en la demanda como tampoco importa negación de lo afirmado en la misma por el sujeto activo. Es decir, el silencio es sólo eso, silencio. En este sentido creo que estamos en lo correcto, efectivamente el silencio no otorga. Quien calla no esta afirmando ni negando lo sostenido por quien pretende algo de aquella parte que no se pronuncia. Sin embargo frente a esta actitud de silencio del sujeto pasivo denominado rebeldía, y ante la situación de que la pretensión de una parte debe encontrar una respuesta traducida en la controversia de los hechos alegados para dar lugar al recibimiento de la causa a prueba, se han elaborado desde antiguo dos sistemas fictos de contestación, la ficta confessio y la ficta litis contestatio antes referidos, los cuales por mucho que se argumente al respecto en defensa de la procedencia y aplicación correcta de uno u otro, en definitiva corresponden a una ficción sin más, puesto que quien calla, en sentido estricto no otorga.

Así las cosas, en nuestras cátedras de derecho se enseña que ante la rebeldía del sujeto pasivo el juez entiende que éste está negando, controvirtiendo de esta manera lo alegado por el sujeto activo en la relación procesal. La controversia de los hechos tiene el efecto de hacer procedente la recepción de la causa a prueba respecto de esos hechos. Es decir, nuestro sistema requiere un legítimo contradictor.

Analicemos esta situación: si el silencio no otorga, ¿porqué el juez recibe la causa a prueba?, y en otros sistemas en que se aplica la ficta confessio o confesión ficta, ¿porqué el juez dicta sentencia estimando la falta de controversia de los hechos? Vamos a nuestro procedimiento laboral, en que el juez ante el silencio del sujeto pasivo en algunos casos dicta sentencia derechamente sin recibir la causa a prueba y en otros, recibe la causa a prueba estimando los hechos como controvertidos. Nuestro procedimiento laboral ¿acoge el sistema de la ficta confessio (al cual adhieren la mayoría de jueces laborales) o de la ficta litis contestatio? Porque si nos remitimos a las normas de procedimiento, estas en ninguna parte nos señalan que el juez deba dictar sentencia derechamente ante la rebeldía del sujeto pasivo, como tampoco existe una norma que prescriba, de todas formas, recibir la causa a prueba.

\footnotetext{
24 En este sentido Chiovenda, José, op. cit. (n. 2), p. 241. Casarino Viterbo, Mario, op. cit. (n. 6), pp. 128-129. Véase también Rodríguez Papic, Ignacio. Juicio Ordinario de Mayor Cuantía. Santiago, Chile: Editorial Jurídica de Chile, 1995, p. 40, que sostiene "Precluido el derecho del demandado de contestar la demanda, se produce lo que en doctrina se conoce como "contestación ficta de la demanda", pero ello no significa que el demandado acepte lo dicho en la demanda, por que en derecho quien calla no otorga, sino que sencillamente no dice nada; por consiguiente, el actor deberá probar los hechos en los que se basa su acción (pretensión). Asimismo Orellana Torres, Fernando. Manual de Derecho Procesal. Procedimientos Civiles Ordinarios y Especiales. Tomo II. Santiago, Chile, Librotecnia, 2006, pp. 203-204.
} 
Miguel Zepeda Pinto/De la rebeldia y sus efectos en el procedimiento laboral de aplicación general

Este es el asunto, dificultad para el juez ya que los propios argumentos de los magistrados en orden a establecer cuando es procedente estimar la inexistencia de hechos controvertidos dando lugar a la sentencia y acogiendo la demanda, es algo incierto y por ende total y absolutamente susceptible de error. En realidad para nosotros, esta contestación ficta en sentido negativo, o negación de lo sostenido por el demandante adoptada en nuestro derecho procesal llamada [ficta litis contestatio] (así como la ficta confessio), es una salida estrecha para el derecho ya que hay una verdad inexpugnable: quien calla no otorga, y no podría ser de otro modo. Podemos constatar que si una parte alega de otra tal cosa accionando judicialmente, $¿$ acaso es esa persona de quien se dice quien deberá demostrar que ello no es tal? ¿O no será que quien dice algo de otro, es quien debe probar que lo sostenido es efectivo? Esto obedece al siguiente razonamiento: quien sostiene algo de otro deberá necesariamente probarlo. Aquel de quien se dice, no tiene la obligación de probar lo contrario, si lo hace bien, pero no está obligado. Ello constituye sí una carga procesal, y únicamente para el evento en que reaccione sin referirse a los hechos alegados se verificará una conformidad tácita o implícita respecto de los mismos.

Por tanto la calidad de legítimo contradictor constituye un error, en el sentido de que el demandado tenga la carga procesal de negar los hechos, como requisito de hacer procedente el desarrollo del procedimiento. Lo anterior referido al supuesto de rebeldía, no así en aquellos casos en que el demandado contestando la demanda no negare todo o parte de lo alegado. De esta manera se explica que se recurra a esta ficción de negación para hacer procedente el recibir la causa a prueba, ya que los hechos deben tener el carácter de controvertidos.

Entonces ante el silencio del requerido, ¿los hechos se deben estimar controvertidos de igual modo? No, sin embargo, será el sujeto activo quien sostiene su pretensión en base a tales hechos, quien deberá probar que lo sostenido de otro es tal. De lo contrario el procedimiento tendría su muerte allí mismo, en la no contestación de la demanda, lo cual importaría que para burlar la acción judicial bastaría no contestar la demanda, puesto que ello implicaría necesariamente que el procedimiento llegara hasta dicha etapa procesal sin posibilidad alguna de resultado.

En otras palabras, ante el silencio del sujeto pasivo se procederá a recibir la causa a prueba no porque el silencio importe que éste este negando, sino porque de estimarse que por el silencio no hay hechos controvertidos, el procedimiento encontraría su término en la etapa de discusión, lo cual importaría la ineficacia absoluta del mismo en orden a accionar para la tutela de derechos. Y ello tiene una lógica, puesto que la referida eficacia traducida en la acción, no se concibe condicionado al actuar del sujeto de quien se pretende. Por ello es que fundamentamos que quien sostiene algo de otra debe necesariamente probarlo. Y ello importa consecuentemente no depender de la conducta de aquella parte de quien se dice y pretende.

Por tanto, y en opinión personal nuestra, la mejor fórmula a implementar, en orden a evitar interpretaciones erróneas, será que el legislador procesal laboral establezca normativamente que se entenderá por la rebeldía de las partes en el proceso, ya sea contestación ficta de negación; o en defecto de ello, que de los efectos ante tales supuestos no quede duda respecto de cual es el sistema doctrinario al que se adhiere. Lo anterior queda plasmado de inmejorable manera en nuestro procedimiento laboral, en que frente a los mismos presupuestos de rebeldía del sujeto pasivo, en unos casos se dicta sentencia sin recibir la causa a prueba y en otros, se recibe la causa a prueba estimando los hechos controvertidos. Entonces en nuestro actual procedimiento laboral, ificta confessio o ficta litis contestatio? Ninguna de las anteriores. 


\section{LA REBELDÍA Y EL MAL PRETENDIDO: ARGUMENTO DE CELERIDAD}

Es de reconocida aceptación por nuestros jueces laborales la idea o postura que adscribe a que el procedimiento laboral reformado apunta principalmente a la celeridad en el proceso evitando el desmedro de aquella parte más vulnerable, en algunas ocasiones. Me refiero al trabajador.

En general, se entiende como doctrina correcta, que en el nuevo procedimiento laboral la rebeldía del sujeto pasivo importa una ficta confessio, lo cual explicaría la actitud del juez en orden a dictar sentencia derechamente sin recibir la causa a prueba. Entre los argumentos más urdidos, se argumenta en el sentido de sostener que el trabajador no puede esperar a que el empleador se apersone al juicio, produciendo con ello una dilación tal en el procedimiento que tendría el resultado de "hacer abandonar" por el trabajador su acción en tribunales, ya que cada día que transcure su situación económica se ve disminuida. Esto que parece muy convincente en su argumento, es en nuestro procedimiento laboral derechamente un mito.

Hoy en nuestro país, quien enfrenta un juicio laboral en calidad de demandado puede contestar o no la demanda. Si contesta, podrá negar los hechos o admitir los mismos en forma expresa, total o parcialmente, o estimarse como admitidos en forma tácita si no se refiere a ellos negándolos. Pero sea como fuese la conducta del sujeto pasivo, el hecho es que el procedimiento en ningún caso se extenderá más allá de lo previsto en la ley. Corroboremos lo dicho. Si el demandado no contesta el juez puede proceder de dos formas: La primera, procediendo a estimar que no hay hechos controvertidos y por ende no recibe la causa a prueba dictando sentencia concluyendo la audiencia preparatoria. La segunda, procediendo a recibir la causa a prueba y fijando audiencia de juicio.

Es del caso señalar, que el argumento de sostener que por la rebeldía del demandado no hay controversia respecto de los hechos alegados por el actor, dictando sentencia sin admitir prueba, no encuentra justificación alguna en el referido argumento de celeridad. En efecto, si nos ponemos en el supuesto de que el demandado se encuentra en rebeldía al no contestar la demanda, y el juez recibe la causa a prueba fijando audiencia de juicio, el tiempo transcurrido será invariablemente el mismo e idéntico que en el supuesto de que el demandado hubiese contestado la demanda negando total o parcialmente los hechos, ya que el juez fijará igualmente fecha para la audiencia de juicio. En dicha audiencia, procederá a dictar sentencia, con la contestación de la demanda en un caso, o en rebeldía del demandado en otro. Por tanto la única celeridad que podemos constatar, se verifica cuando frente a la rebeldía, el juez dicta sentencia sin recibir la causa a prueba. Pero debemos admitir, que para el caso de haber recibido la causa a prueba, el transcurso de tiempo sería idéntico, con rebeldía o sin ella.

\section{LA VALORACIÓN DE LA PRUEBA Y SENTENCIA}

Un punto importante a tratar, corresponde a la valoración de la prueba en la sentencia. Como sabemos, en nuestro procedimiento laboral rige el sistema de la sana crítica, el cual otorga al juez un espacio más amplio dentro del cual moverse para fundar su decisión. Una de las cuestiones que más llama la atención corresponde a la fundamentación de las sentencias, ejercicio legal que se ha ido deteriorando con el transcurso del tiempo y al que de alguna manera nos hemos acostumbrado sin reparar demasiado en ello. El ejercicio de la potestad facultativa por parte del juez respecto a la admisión tácita de hechos por aplicación del artículo $453 \mathrm{~N}^{\circ} 1$ inciso $7^{\circ}$ del CT, 
Miguel Zepeda Pinto/De la rebeldia y sus efectos en el procedimiento laboral de aplicación general

ha generado una fecunda jurisprudencia que da cuenta de una insoslayable precariedad en la fundamentación de las sentencias.

En efecto, nuestros tribunales laborales ante la rebeldía del sujeto pasivo, resuelven mayoritariamente en orden a la aplicación del razonamiento de dar por establecido la falta de controversia respecto de los hechos alegados por el demandante en relación con la admisión tácita de los mismos, procediendo a dictar sentencia derechamente en la audiencia preparatoria. Ello se puede apreciar en causas como RIT O-45-2011 del Juzgado de Letras del Trabajo de Antofagasta antes citada, cuya sentencia para dar lugar al despido indirecto del artículo 171 del CT, enumera dentro de las circunstancias para su procedencia, que el empleador haya incurrido en la causal de desahucio contemplado en el artículo $160 \mathrm{~N}^{\circ} 7$ del CT. No obstante, el fallo no da cuenta en modo alguno de algún antecedente que de cuenta de la efectividad de la conducta alegada por el actor, procediendo a motivar la decisión en orden a acoger la demanda lisa y llanamente por aplicación de la facultad legal, calificando además el término del contrato de trabajo por incumplimiento grave.

Lo anterior, lejos de mostrar un contenido reflexivo en orden a ser el resultado del examen cierto de antecedentes que hagan verosímil establecer que hay fundamentos serios en orden a la efectividad de los hechos alegados, traducido ello en la causal invocada, no es ni más ni menos que la interpretación incorrecta y sin razonamiento alguno de la estimación facultativa del juez, que si bien discrecional en su ejercicio, para el caso que nos ocupa denota una errada aplicación. Ello toda vez que el citado fallo no contiene fundamentación alguna en este sentido, que de cuenta a lo menos del incumplimiento que el actor aduce. Entonces no sin justa razón podemos sostener que la sentencia propuesta no contiene siquiera un rastro respecto del cual el juzgador pueda hacer uso para hacer procedente la aplicación de dicha facultad contenida en la norma en que funda su decisión. Existen muchos otros casos en que lo señalado se verifica de modo patente.

Por otra parte y a modo de ejemplificar lo sostenido logrando un contraste jurídico, podemos analizar aquellos casos en que encontrándose en rebeldía el sujeto pasivo, el juez resuelve en la aplicación de la citada facultad potestativa como consecuencia de antecedentes aportados en parte de prueba por la demandante, lo cual resulta acorde con el verdadero espíritu de la norma, y que sin embargo no siempre importa acoger la pretensión.

En efecto, así en causa RIT O-58-2011 del Juzgado de Letras del Trabajo de Antofagasta ${ }^{25}$, la actora allegó al proceso prueba instrumental que da cuenta de los supuestos jurídicos que hacen procedente el petitum. Conforme a ello, la sentencia razona en mérito de los antecedentes aportados, fundando su decisión precisamente en que ante la rebeldía de la demandada no es posible analizar motivos o causas que determinen por el rechazo de la pretensión. En otras palabras lo que el juez está diciendo, es que de haber aportado prueba la demandada desvirtuando los presupuestos de hecho y de derecho esgrimidos por la actora, la decisión podría ser otra; pero de que sin embargo no cabe analizar ello en atención a la rebeldía de la misma.

\footnotetext{
25 "PRIMERO: Que compareció la sociedad Comercial Santa Elena S.A., y dedujo demanda laboral en procedimiento de aplicación general de desafuero, solicitando al Tribunal se le autorice a despedir a la trabajadora Raquel Rocío Prado Flores, por la causal del artículo $159 \mathrm{~N}^{\circ} 4$ del Código del Trabajo, en atención a que goza fuero maternal. Todo ello con costas. SEGUNDO: Que, dońa Raquel Rocio Prado Flores, no compareció al proceso, de tal manera que el juicio se siguió en su rebeldía". "SEXTO: Que, del análisis de las pruebas acompañadas a la causa, de conformidad a las reglas de la sana crítica y teniendo, especialmente presente que la trabajadora no contestó la demanda, y por ende resulta factible tener por reconocidos tácitamente los hechos expuestos en la demanda, se comprueba que el contrato de trabajo que liga a las partes es de plazo fijo cuyo vencimiento ocurrió el día 15 de febrero de 2011, de tal modo que se acogerá la demanda otorgando la autorización solicitada". OCTAVO: "Que, ante la rebeldía de la demandada, no es posible para este sentenciador analizar motivos o causas que determinen el rechazo de la autorización, de tal modo que se concederá ella, facultando al empleador para despedir al trabajador por la causal del artículo 159 N4 del Código del Trabajo”.
} 
Pero eso no es todo, podría darse el supuesto que los antecedentes aportados por la actora no revistan el carácter suficiente para formar convicción en el juez resolviendo en dar lugar a lo pedido ${ }^{26}$. Lo anterior sólo tiene una respuesta: Lo procesalmente idóneo o más acertado, se traduce en recibir la causa a prueba estemos o no frente a la rebeldía del sujeto pasivo. Porque de lo contrario, sobre que base estimamos los hechos como razonablemente efectivos para que tengan el mérito de hacer procedente la admisión tácita en la sentencia.

El fallo así expuesto, cumple con la exigencia legal de resolver en mérito de fundamentar las razones o motivos que determinan su decisión, y en el podemos verificar valoración de la prueba y no una mera referencia o señalamiento de la estimación facultativa de hechos como fundamento de la sentencia.

Por tanto, se puede verificar que para casos de rebeldía del demandado, hay sentencias que razonan sobre la base de la prueba aportada por la demandante, lo que se traduce en sostener que en la calidad de la prueba se debe observar necesariamente, un estándar probatorio mínimo. ${ }^{27}$

Un buen ejemplo de lo dicho se puede corroborar en causa RIT O-30-2011 del Juzgado de Letras del Trabajo de Copiapó ${ }^{28}$ que ante el supuesto de rebeldía, contiene una valoración de la prueba plasmada en la fundamentación de la sentencia en perfecta armonía con lo que debemos entender por el sistema de valoración de la sana crítica. Por el contrario, cuando el fallo se basa en la aplicación sin más de la potestad legal, ¿que conocimientos científicamente afianzados se pueden esgrimir? ¿las máximas de cual experiencia?

Por otra parte debemos entender que la expresión "como tácitamente admitidos", hace alusión a algo similar pero no igual. El adverbio "como" según el Diccionario de la Lengua Española, implica una comparación, una equivalencia. El juez fallará, "haciendo las veces" que el demandado hubiera admitido los hechos de la demanda. Pero lo real y concreto es que el demandado no los ha admitido ${ }^{29}$. Ello hace necesariamente aconsejable que el juez tenga antecedentes que no dejen lugar a dudas que el derecho reclamado corresponde de quien lo reclama.

Otro punto muy importante a tener en cuenta respecto al ejercicio de esta facultad estimativa del juez en la sentencia, dice relación con su alcance y sus limitaciones. Efectivamente, porque frente a la rebeldía del sujeto pasivo podría el juzgador estimar sólo alguno o algunos de los hechos alegados como tácitamente admitidos, lo cual supone necesariamente la existencia de prueba para llegar a tal decisión; evento en el cual la sentencia podría tener un desenlace totalmente diverso de aquel que en razón de la rebeldía se resolviera por acoger la demanda derechamente en razón de estimar los hechos -todos- como tácitamente admitidos. Claro está, dicho raciocinio importa una

\footnotetext{
26 En dicho sentido, Corte de Apelaciones de Talca, 18 de marzo de 2011, Rol 12-2011. [en línea]. <www.poderjudicial.cl>. [consulta: 20 julio 2012].

27 Fuentes Maureira, Claudio, op. cit. (n. 11), p. 14.

28 Juzgado Letras del Trabajo de Copiapó. [en línea].< www.poderjudicial.cl >.[consulta:1 junio 2011]. QUINTO: Que el Artículo $453 \mathrm{~N}^{\circ} 1$ inciso $7^{\circ}$ del Código del Trabajo, expresa que, en aquellos casos en que la parte demandada omitiere el trámite de contestación de demanda y asimismo se mantuviese en rebeldía en el transcurso del juicio, el Tribunal podrá en la sentencia definitiva entender como reconocidos tácitamente los hechos contenidos en la demanda, ingresados por la parte demandante; que desde esa perspectiva, siendo facultativo para este Tribunal, esta Magistratura entenderá en este estadio procesal que efectivamente en la especie la parte demandada ha reconocido tácitamente los hechos contenidos en la demanda y los fundamentos de derecho que ella contiene.SEXTO: Que en mérito de lo señalado en el considerando supra citado y todo aquello relacionado con la prueba documental incorporada por la parte demandante, el Tribunal ha arribado a la convicción de los siguientes antecedentes.... SÉPTIMO: Que en mérito de lo razonado precedentemente, este Tribunal ha arribado a la convicción de que efectivamente en la especie la trabajadora incurrió en incumplimiento grave de las obligaciones que emanaban de su contrato de trabajo.

29 SENTENCIA de la Corte de Apelaciones de Valparaíso, 23 de septiembre de 2009, rol № 345-2009. [en línea]. <www. poderjudicial.cl.> [consulta: 27 mayo 2011].
} 
Miguel Zepeda Pinto/De la rebeldía y sus efectos en el procedimiento laboral de aplicación general

labor que debemos esperar de nuestros jueces, porque como vemos a menudo, ante el supuesto de rebeldía ello generalmente no acontece. Sencillamente podemos observar que para el caso de estimar por el juez sólo alguno o algunos de los hechos alegados como tácitamente admitidos, dicho ejercicio podría dar lugar a sentencias que dieren lugar a la demanda sólo en aquella parte que se estimó procedente la admisión facultativa, y ello es muy distinto a lo que está sucediendo hoy en nuestra jurisprudencia laboral.

Dicho esto, podemos observar claramente y no sin preocupación que en los casos en que no se recibe la causa a prueba por la rebeldía del demandado, derechamente los jueces laborales fundan su decisión en la potestad facultativa de admisión tácita de hechos, es decir en una norma legal que en modo alguno, así como en ninguna otra del mismo cuerpo legal, prescriba que ante la rebeldía se omita la prueba. Otra cosa muy distinta, se contiene en el ya citado artículo $453 \mathrm{~N}^{\circ}$ 3 inciso segundo del CT, que en sus efectos es similar pero que no es lo mismo, en razón de que los presupuestos de procedencia en su aplicación son radicalmente distintos, ya que para el caso de no haber hechos sustanciales, pertinentes y controvertidos, el tribunal dará por concluida la audiencia y procederá a dictar sentencia. Pero este supuesto contempla abiertamente la contestación de la demanda como requisito de procedencia, y no se refiere al caso de verificarse rebeldía por el demandado.

Creemos por lo expuesto, que el razonamiento de nuestros tribunales laborales está encaminado en una errónea interpretación de la facultad legal, como pasaremos a explicar en nuestro último apartado. En este sentido, se puede constatar que la jurisprudencia que da cuenta de lo sostenido en este trabajo, obedece a una política procesal que en su aplicación produce efectos nocivos, ya que no sólo transgrede el debido proceso garantido a nivel constitucional, sino que además y muy por sobre lo anterior, no se corresponde con las necesidades de una sociedad que tiende cada vez más, a través precisamente de las diversas reformas de procedimiento, a una mejor tutela de derechos y mayor certeza jurídica.

\section{LA ADMISIÓN TÁCITA DE HECHOS PROPIAMENTE TAL Y SU ERRÓNEA APLICACIÓN}

Antes nos referimos a la admisión tácita de hechos y a la ficta confessio con el fin de analizar sus semejanzas y diferencias, concluyendo que a pesar de sus semejanzas no son lo mismo. Pues bien, podemos afirmar que la norma del artículo $453 \mathrm{~N}^{\circ} 1$ párrafo séptimo del CT, se corresponde efectivamente con una admisión tácita de hechos. Sin embargo y conforme se pasará a explicar, nuestros jueces laborales para un gran número de casos, realizan una errada interpretación de la misma en su aplicación.

La admisión de hechos puede ser expresa o tácita. La admisión expresa, es un acto procesal por el cual una parte reconoce la efectividad de los hechos expuestos por la contraria, y cuyo efecto es que ésta última quede relevada de probar los hechos admitidos por la primera, resultando innecesaria cualquier forma de prueba de los hechos admitidos los cuales el juez debe tenerlos por acreditados. Con la admisión tácita ocurre el mismo efecto y se diferencia de la expresa en que ella se aplicará en los casos que señala la ley ${ }^{30}$.

Sin embargo para estar frente a una admisión tácita, requisito necesario será que la parte respondiendo o reaccionando frente a los hechos alegados, no se pronuncie en modo alguno res-

30 Carrasco Poblete, Jaime, op. cit. (n. 15), p. 19. 
pecto de todos o algunos de los mismos. Cuando ello se verifica de este modo, podemos hablar de una admisión tácita propiamente tal, ya que el requerido con su conducta está manifestando implícitamente su conformidad respecto de aquello de lo cual no se refirió pudiendo hacerlo. En cambio cuando el requerido nada dice, se verifica la contumacia. En este caso no podemos sostener que haya operado una admisión tácita de los hechos alegados, puesto que en dicho supuesto jurídico el silencio no otorga. El requerido no esta admitiendo, ni confesando, como tampoco negando. De suerte tal que el juez podrá estimar los hechos como sustanciales, pertinentes y controvertidos si así lo considera, si ello es así, se encuadra dentro de la figura doctrinaria de la ficta litis contestatio. Por el contrario, de estimarse por el juez que ante la rebeldía del requerido se entiende que éste confiesa como efectivos los hechos de manera ficta, no existiendo controversia respecto de ellos resultando innecesaria la prueba, procederá a dictar sentencia derechamente. Este supuesto corresponderá a la figura doctrinaria de la ficta confessio, pero no a una admisión tácita de hechos, ya que el silencio absoluto inexpugnablemente no otorga.

Corroborando lo dicho, podemos observar que no resulta correcto sostener que para supuestos diferentes el resultado sea el mismo. De este modo, si el demandado no contesta la demanda, no resultará procedente el mismo efecto jurídico procesal que para el evento en que contestando no negare algunos de los hechos contenidos en la demanda. Sin embargo la redacción del artículo $453 \mathrm{~N}^{\circ} 1$ párrafo séptimo contempla ambos casos, "cuando el demandado no contestare, o de hacerlo, no negare en ella algunos de los hechos contenidos en la demanda”, con el mismo efecto de poder estimarlos como tácitamente admitidos. Creemos que allí radica el error que lleva a una confusión en la interpretación de la citada norma y por ende en su aplicación, ya que estimamos que en el segundo supuesto nos encontramos frente a una admisión tácita de hechos propiamente tal, no así en el primero, aún cuando la norma contenga a ambos. En este sentido, para el primer supuesto, en que el demandado no contesta la demanda, en nuestra jurisprudencia laboral se verifican los efectos de una ficta litis contestatio cuando se recibe la causa a prueba, y al mismo tiempo los efectos de una ficta confessio cuando se dicta sentencia derechamente. Concluimos así, que frente a una misma conducta del demandado, no puede haber efectos procesales diversos.

\section{LA REBELDÍA EN EL PROYECTO DE REFORMA PROCESAL CIVIL: UN ESPÍRITU Y OTRO}

Una particularidad subyace además de todo lo tratado hasta aquí, y de que resulta imposible pasar por alto sin referir unas palabras al respecto. Si nos detenemos en analizar el reciente Proyecto de Reforma Procesal Civil, en su Libro Segundo referido a los Procesos Declarativos, Título I, Juicio Ordinario, Capítulo $3^{\circ}$ De las Actitudes del Demandado Frente a la Demanda, el artículo $264^{31}$ al tratar la rebeldía, prescribe: "Cuando el demandado debidamente emplazado no comparezca dentro del plazo correspondiente, el tribunal tendrá por evacuado el trámite de contestación de la demanda y el proceso se seguirá en su rebeldía, por el sólo ministerio de la ley". $\mathrm{El}$ inciso segundo dispone algo que constituye un avance tremendo en materia de procedimiento al disponer: "La rebeldía del demandado importará una negación de los hechos afirmados por el actor en su demanda, pero no podrá rendir prueba en juicio, salvo en la forma y condiciones previstos en el artículo 276".

31 Proyecto de Reforma Procesal Civil. Año 2012. [en línea]. < www.bcn.cl.> [consulta: 10 febrero 2012]. 
Miguel Zepeda Pinto/De la rebeldia y sus efectos en el procedimiento laboral de aplicación general

Si reflexionamos respecto de esta norma, podemos observar que la misma contiene dentro de sus efectos de manera implícita, el resguardo de un principio fundamental del Derecho; la buena fe. Podemos observar que ante la rebeldía del demandado, si bien establece normativamente una negación ficta de los hechos dando lugar a la prueba, evitando con ello posibilidades de error en la decisión del sentenciador, al mismo tiempo establece para el rebelde la imposibilidad de rendir prueba en el juicio, lo cual pone un límite a la posibilidad del demandado en orden a la intencionalidad implícita que éste pueda tener en orden a sacar provecho de su inactividad. En cambio, nuestro procedimiento laboral no contempla dicho efecto, de esta manera, a pesar de no contestarse la demanda, el rebelde podría igualmente rendir prueba en el evento de resolver el juez por ella, asistiendo por supuesto a la audiencia preparatoria.

Conforme lo anterior, podemos concluir que si el citado artículo $453 \mathrm{~N}^{\circ} 1$ párrafo $7^{\circ}$ del CT fuese modificado bajo el tenor que contiene la norma antes referida, se estaría anulando con ello toda intensión del rebelde en orden a que su conducta de inacción si fuese de mala fe, produzca el efecto de poner al rebelde en una situación de ventaja respecto de su contraparte. Efecto que pensamos, nuestro legislador procesal ha buscado, sólo que de modo imperfecto.

Esta norma despeja toda duda, lo procesalmente más acertado frente a la rebeldía del demandado se traduce en seguir el proceso en rebeldía de aquel. Más aún y a objeto de evitar cualquier error de interpretación -y creemos con justa razón atendido el actual procedimiento laboral en su aplicación e interpretación para el caso propuesto-; de parte del juzgador, el inciso segundo previendo establecer de la mejor manera posible un debido proceso en armonía con los principios que lo rigen, deja en claro que la rebeldía del demandado importará una negación de los hechos afirmados por el actor en su demanda. Con ello se está propendiendo a una manifiesta celeridad en el procedimiento, no sólo en cuanto al desarrollo del mismo sino que fundamentalmente a fin de evitar recurrir por vulneración del debido proceso ante el tribunal ad quem, con la consiguiente dilación en el resultado definitivo del juicio.

Creemos que el Proyecto de Reforma Procesal Civil, contiene algo más de elaboración doctrinal presente plasmado en su espíritu. Conforme hemos dicho, nuestros jueces laborales ante la rebeldía del demandado, en forma mayoritaria dan lugar a la sentencia derechamente sin recibir la causa aprueba, fundando acoger la demanda en la falta de hechos sustanciales, pertinentes y controvertidos. Sin embargo nuestro Proyecto de Reforma Procesal Civil de manera muy acertada, eleva a lo sublime el sentido lógico en lo jurídico al disponer en su artículo 266 inciso segundo al tratar sobre el allanamiento a la demanda que: "En caso de allanamiento total, o cuando el demandado no contradiga en materia sustancial y pertinente los hechos afirmados por el actor en su demanda, el tribunal, concluida la audiencia preliminar, deberá dictar sentencia definitiva en los términos establecidos en el artículo 283, sin necesidad de prueba ni de ningún otro trámite". Este presupuesto no contempla rebeldía, no obstante previene en su inciso tercero y final: "Corresponderá, por el contrario, seguir los trámites del proceso respectivo, si el allanamiento fuere parcial, si la cuestión planteada fuere de orden público o se tratare de derechos indisponibles".

Efectivamente ambos incisos, dejan total y absolutamente en claro la prohibición legal de dictar sentencia de inmediato sin seguir los trámites del proceso cuando se verifica la contumacia del demandado.

Como podemos apreciar, lo expuesto va en sentido totalmente contrario a la interpretación de que hacen nuestros jueces laborales frente al supuesto de rebeldía en nuestro procedimiento laboral, situación de la que no podemos desentendernos, y que amerita por las razones expuestas una modificación al precepto legal en estudio. 


\section{A MODO DE CONCLUSIÓN}

Si bien la estimación facultativa de admisión tácita de hechos por la rebeldía del demandado obedece a una norma legal, y por ende lícitamente aplicable por el juez laboral, la aplicación que de la misma se observa en la actual jurisprudencia dan cuenta ciertamente de una errada interpretación en su procedencia. Ello se ha hecho notar en una evidente falta de fundamentación de las sentencias, respecto de las cuales no puede sostenerse que sean el resultado de una valoración de la prueba conforme a la sana crítica. De esta manera lo no razonado no puede servir de fundamento válido para la decisoria litis.

Hemos llegado a una época, en la cual los sistemas tradicionales de creación doctrinaria relativos a la exigencia de un legítimo contradictor para la procedencia del recibimiento de la causa a prueba, no van a la par con la reforma implementada en nuestro procedimiento laboral, teniendo por efecto una ambigüedad en la determinación del cuando los hechos alegados por el actor deben considerarse controvertidos. Lo cual es criticable puesto que ante tal escenario podemos constatar una evidente falta de certeza jurídica que denota además síntomas de inconstitucionalidad.

Nuestra jurisprudencia laboral devela una realidad procesal cierta: la rebeldía del demandado no determina el que los hechos se estimen como controvertidos o no controvertidos. Por ende, y en la misma lógica, mal podría argumentarse por nuestros jueces en el sentido que frente a la rebeldía del demandado se proceda a estimar que no hay hechos controvertidos no recibiendo la causa a prueba dictando sentencia derechamente.

En definitiva, no es la admisión tácita de hechos lo que determina el resultado de acogerse la pretensión del actor dando lugar a lo pedido, sino que en realidad, lo que produce tal consecuencia, es el razonamiento del juez de dar por establecida la falta de hechos controvertidos, ante la rebeldía del demandado. El problema radica entonces en que el sentenciador, en razón de una equivocada interpretación de la norma, se sirve para fundar la falta de hechos que revistan tal carácter, cosa que no puede determinar en dicho momento procesal. Es el legislador quien señala -en perfecta concordancia con lo razonado-, que el momento oportuno para su aplicación, corresponde a la etapa de sentencia. ${ }^{32}$ Y ello no está sucediendo en nuestros tribunales del trabajo. Esto tiene una explicación palpable: la citada norma contiene para dos supuestos procesales distintos, un mismo efecto jurídico. Para el segundo supuesto en que el requerido contesta pero no se refiere a algunos de los hechos, se verifica una admisión tácita de hechos propiamente tal, perfectamente procedente. Sin embargo para el primer supuesto de rebeldía total por la no contestación de la demanda, no podemos sostener la procedencia de una admisión tácita de hechos, ya que el silencio no otorga, y por lo mismo, en ocasiones opera una negación ficta de los mismos o ficta litis contestatio.

Respecto a si esta facultad del juez, de estimar los hechos como tácitamente admitidos corresponde a una sanción, nosotros estimamos incorrecta dicha afirmación, puesto que para el caso de no contestación de la demanda no estamos frente a una admisión tácita de los hechos. Más por otra parte, si contestando, el requerido no se pronunciare respecto de algunos hechos, hay

\footnotetext{
32 "SEXTO: Que de lo anterior, es posible desprender que el silencio del demandado al momento de contestar la demanda, cumple un rol, es capaz de producir una presunción en contra de quien lo manifiesta, toda vez que, como se seńaló, si el demandado no la contesta, el juez tiene la facultad de estimar los hechos contenidos en la demanda como tácitamente admitidos, facultad que según seńala la citada disposición, se ejerce en la sentencia definitiva, y no en la audiencia preparatoria”. Corte de Apelaciones de Antofagasta, 26 septiembre de 2011, ROL 144-2011. [en línea]. <www.poderjudicial.cl>. [consulta: 20 julio 2012].
} 
Miguel Zepeda Pinto/De la rebeldia y sus efectos en el procedimiento laboral de aplicación general

aquí una admisión tácita de hechos propiamente tal, pero dicha admisión tácita en su naturaleza jurídica y efectos, no se corresponde a una sanción procesal, sino al efecto propio de conformidad implícita ante los hechos invocados. Además, para sostener la idea de una sanción, la admisión tácita así establecida en la sentencia debiese verificarse sin excepción ante el supuesto de rebeldía, ya que no podría quedar al arbitrio del juez, dar o no lugar a su aplicación. Si de esta manera se procediere, estaríamos ante una arbitrariedad. En definitiva, potestad facultativa y sanción, no son lo mismo.

Por último y para terminar, notable se vislumbra nuestro Proyecto de Reforma Procesal Civil, que paradojalmente establece un sentido y una tratativa totalmente inversa a la institución de la rebeldía en este supuesto, no solo respecto del procedimiento laboral, sino que derechamente respecto a la política e interpretación de nuestros jueces laborales frente a la misma.

\section{BIBLIOGRAFÍA}

Anabalón Sanderson, Carlos. El Juicio Ordinario de Mayor Cuantía. Santiago, Chile: Editorial Jurídica de Chile, 1954, p. 173.

Calamandrei, Piero. Instituciones de Derecho Procesal Civil. Vol. I. Buenos Aires, Argentina: Editorial El Foro, 1996.

Carnelutti, Francesco. Instituciones del Proceso Civil. Vol. I. -4º edición-. Buenos Aires, Argentina: Librería El Foro, 1997.

Carrasco Poblete, Jaime. La Rebeldía en el Procesos Civil y Laboral. Santiago, Chile: Abeledo Perrot Legal Publishing, 2010 .

Casarino Viterbo, Mario. Derecho Procesal Civil. Tomo IV. Santiago, Chile: Editorial Jurídica de Chile, 1997.

Chiovenda, José. Principios de Derecho Procesal Civil. Tomo II. Buenos Aires, Argentina: Editorial Reus, 1925, pp. 267-268.

Fernández Toledo, Raúl. Las facultades y deberes del juez en materia probatoria en el proceso laboral. Análisis crítico. Santiago, Chile: Thomson Reuters PUNTOLEX, 2011.

Fuentes Maureira, Claudio. "Consideraciones en torno a la idea del estándar de convicción en el Proceso Civil”. En: Leturia I., Francisco J. (Editor). Justicia Civil y Comercial: Una Reforma Cercana. Santiago: Ediciones Libertad y Desarrollo, 2011.

Orellana Torres, Fernando. Manual de Derecho Procesal. Procedimientos Civiles Ordinarios y Especiales. Tomo II. Santiago, Chile, Librotecnia, 2006.

Orellana, Fernando; Pérez Ragone, Álvaro. "Radiografía de la rebeldía en el proceso civil: Tópicos hacia una adecuada regulación en la nueva justicia civil”, en: Ius et Praxis, año 13, no 2, 2007.

Rodríguez Papic, Ignacio. Juicio Ordinario de Mayor Cuantía. Santiago, Chile: Editorial Jurídica de Chile, 1995. 